\title{
IMPACT OF CO-CREATION FOOTWEAR WORKSHOPS ON OLDER WOMEN IN ELDERLY CENTERS IN HONG KONG
}

\author{
Mei-ying Kwan, Kit-lun Yick, Yan-yan Wang \\ The Hong Kong Polytechnic University \\ Correspondence: meiying.aa.kwan@polyu.edu.hk
}

\section{ABSTRACT}

\section{BACKGROUND}

The use of appropriate footwear could reduce the risk of falls among the geriatric population. However, the elderly is generally reluctant to accept new footwear designs particularly with the incorporation of fabrication materials and functional design features that are perceived to be less comfortable. Co-creation activities that encourage user involvement during the product design process and development can therefore address this issue and provide unique benefits and better value for users, increase acceptance, and even lead to positive perception as well as positive psychological impacts, thereby increasing the practical use of newly designed footwear.

\section{OBJECTIVE}

This study aims to investigate the impact of hands-on footwear workshops on perceived functionality of geriatric footwear for older women.

\section{METHOD}

Footwear co-design workshops for older women were carried out in two elderly centers in Hong Kong. Twenty-one healthy females between 64 and 80 years old (mean: 71; SD: 4.2), were recruited. Subjects were invited to decorate the prescribed geriatric footwear prototype and discuss their ideas on footwear design in a group of three. They were surveyed after completing the footwear decoration.

\section{MAIN OUTCOME MEASURES}

The perceptions of the subjects on the geriatric footwear and related design features were analysed.

\section{INTRODUCTION}

Falling and gait unsteadiness are common problems of the elderly. It is widely believed that age-related deterioration of the neuromuscular system is closely related to increased postural sway, poor balance control and ultimately higher risks of falling. Reports have found that older women are at higher risk of falling than men. [1] However, appropriate footwear can help to prevent the elderly from falling. [2-4] For example, open-toe mule slippers are a popular type of footwear worn at home, and especially favored by older women. They are light in weight and convenient to wear. Nevertheless, prolonged use of footwear with little support that is loosely secured to the feet may lead to foot pain, 
deformity and difficulties in maintaining balance. Suitable footwear can protect the elderly from falls and foot abnormalities, thereby reducing the risk of fractures and other serious injuries. Therefore, they are a crucial product to protect the safety of the elderly.

Footwear is intended to offer the first line of protection to the feet. Walking in slippers made of soft footbed material with high compressibility provides better pressure attenuation but requires more muscle activity to maintain postural stability as compared to more rigid footbed materials. Footwear components such as semi-rigid midsole materials, proper arch support, stiff heel collar as well as slip resistance outer sole are therefore recommended in geriatric footwear designs. Many older people, however, are reluctant to accept changes regardless of the increased stability offered by proper footwear. [3] They may prefer to walk barefoot or in socks for comfort but face the risk of a ten-fold increase in falling.

Fashion products not only serve functional purposes, but also involve many psychological factors such as selfesteem and self-image. [5] A research article compared psychological factors, design preferences and fashion experiences across gender in Hong Kong. It found that in addition to function, older women are very concerned about the product design, appearance and characteristics of fashion items. [6] A study also showed that older women are primarily driven by the aesthetics and comfort of footwear. [7] Enhancing the design of conventional footwear might be the first step for improving the practical use and perception of geriatric footwear.

The traditional footwear design process neglects the demand of older people for improved products. [6] The lack of participation of elderly users in the product design and development process may lead to their reluctance to use the product. [8] Recently, the concept of collaborative design (co-design) is becoming an increasingly popular method for designers to better meet the needs of their users. The term refers to the creative product that designers and users create together during the development process of a product design. [9] The positive impact of co-design is evidenced in the literature on service design projects for technology products, in which customers and the relevant organizations have opportunities to experience creativity and collaboration, and the ability of the organization to innovate and change is enhanced. [10]
However, the possible impacts of co-design on footwear development have not been fully reported. The aim of this study is to therefore investigate the psychological value of

co-design workshops for older women. The impacts of codesign on the perception of geriatric footwear are also discussed. It is anticipated that the findings of this study will enhance current understanding of the psychological changes in older women after taking part in a co-design process, and provide insights that enhance the use of footwear worn at home for foot protection.

\section{EXPERIMENTAL}

\section{SETTING}

The appearance design of geriatric footwear has great importance in product development. In this research study, footwear workshops that feature co-creation and decoration of footwear were carried out in two elderly centers in Hong Kong. The elderly subjects were invited to take part in a workshop to decorate shoes after they completed a wear trial for geriatric footwear and each individual was prescribed a geriatric footwear prototype for a wear trial of 4-6 weeks. The subjects were invited to attend a workshop on co-creating footwear which focused on decorating the shoes. Discussion on the footwear design and modifications was encouraged and facilitated. Upon completion of the discussion, the subjects were invited to complete an evaluation questionnaire.

A poster of the footwear workshops was designed (Figure 1), in which examples of shoe designs were shown to inspire the subjects on the design elements for the footwear (Figure 2). Decorative materials, such as different types of flower ornaments, pearl embellishments, lace, fringes, embroidery, applique, beads, etc. were made available at the workshops (Figure 3). Colors that matched the original color of the shoes were used, such as blue and red schemes. To encourage discussion and participation, groups of three were formed in each workshop. With the support of the facilitator, the subjects first discussed the original design of the geriatric footwear. Then, new design features and selected decorative materials, as well as different methods and tools for attaching the shoe decorations were reviewed and analysed. Upon completion of the footwear decoration component, a questionnaire survey was disseminated for completion. The perceptions of the subjects on the geriatric footwear and related design features were subsequently analysed. 
FIGURE 1: POSTER FOR WORKSHOP ON FOOTWEAR CO-CREATION AND DECORATION

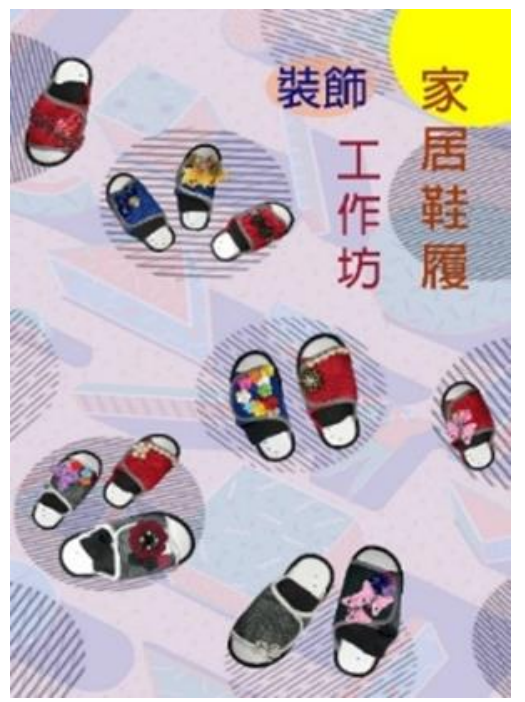

FIGURE 2: PROTOTYPE EXAMPLES OF DECORATED FOOTWEAR

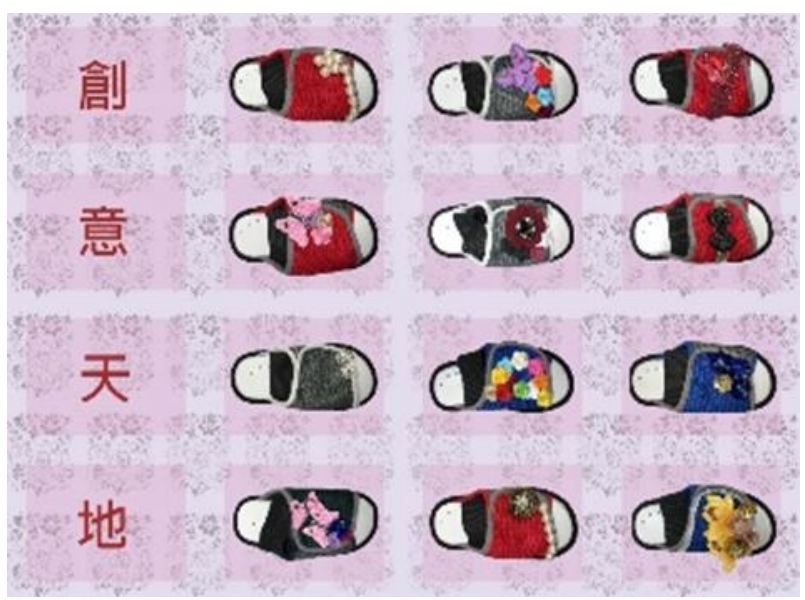

FIGURE 3: DECORATIVE MATERIALS OFFERED AT WORKSHOP

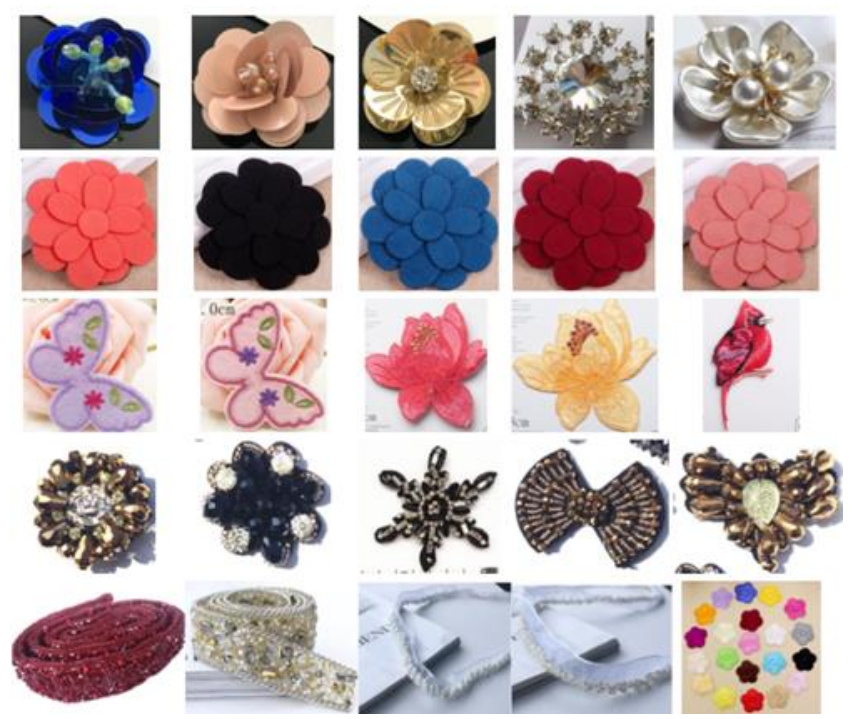




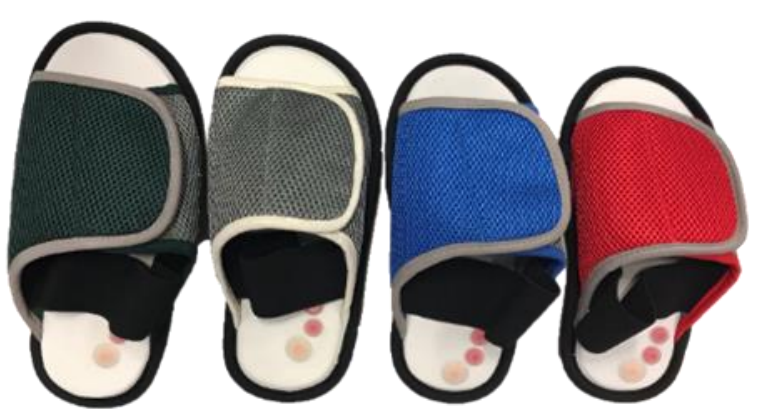

\section{DATA COLLECTION}

A questionnaire was conducted which used a 7-point Likert scale (in which 1 denotes "strongly disagree" and 7 denotes "strongly agree"), and yes/no and open-ended questions. The response and perceptions of the subjects on 'satisfaction felt during the workshop', 'feelings and thoughts during the decoration process, and 'ideas during the workshop and attitude towards the workshop' were collected and analysed.

\section{RESULTS AND DISCUSSION}

The questionnaire results are provided in Tables 1 and 2. The overall results in the two tables show that the subjects enjoy the co-design process and $95 \%$ feel satisfied with their finished footwear prototype. Choosing the design elements, working with the workshop facilitators, and completing the decoration process are considered as the most satisfactory components in the co-creation workshops.

In response to the satisfaction from the co-creation process, $90 \%$ of the respondents indicated that they are able to express themselves based on the decoration process and none of them did not enjoy the process. Only $14 \%$ experienced challenges during the co-design process. The rest, or $86 \%$ of the subjects, agreed that they are able to express their creativity in the workshop. The result is similar to the study which showed that a strong correlation is found between satisfaction and self-expression and between self-esteem and self-confidence amongst the elderly participants. [6] The decoration workshop enhanced their self-esteem and confidence in footwear creation and design creativity.

In terms of their feelings, all of the subjects felt relaxed and happy during the entire decorating process. Furthermore, $95 \%$ of the respondents claimed that they are able to fully engage and focus on the footwear design process. In terms of ideas and attitude during the decoration process, $90 \%$ of the respondents indicated that they like to discuss their ideas with other elderly individuals. This result is consistent with the research which showed that most women like to create art in a social context, where they can gain recognition and appreciation for their artwork. [11] In addition, $81 \%$ of them agreed that the design process allow use of eye- hand coordination, increased their motor skills, as well as increased finger sensitivity and dexterity.

At the co-design workshops, the subjects experienced a process of internal self-discovery, acceptance and expression. They discussed the aesthetic needs of their footwear with the workshop facilitators. The workshops allow group creativity and increase user satisfaction and loyalty to the product. [10] The level of engagement with the footwear prototype was therefore enhanced. The pleasure and satisfaction experienced at the workshop greatly increased product acceptance. It is expected that older people will rely more on products that are psychologically meaningful. [12] The use of appropriate footwear by the elderly could be therefore increased by incorporating a co-design process in footwear production. 
TABLE 1: FEEDBACK ON PERSONAL EXPERIENCES AT FOOTWEAR WORKSHOPS

\begin{tabular}{|c|c|c|c|c|c|c|c|}
\hline & \multirow[t]{3}{*}{ ITEMS } & \multirow[t]{3}{*}{$\mathbf{N}$} & \multirow[t]{3}{*}{ MEAN } & \multirow[t]{3}{*}{ SD } & \multicolumn{3}{|c|}{$\begin{array}{l}\text { PERCENTAGE DISTRIBUTION } \\
(\%)\end{array}$} \\
\hline & & & & & $1-3$ & 4 & $5-7$ \\
\hline & & & & & $\begin{array}{l}\text { DISAGR } \\
\text { EE }\end{array}$ & $\begin{array}{l}\text { NEUTRA } \\
\text { L }\end{array}$ & AGREE \\
\hline a & $\begin{array}{l}\text { I can focus and engage in the creative } \\
\text { process. }\end{array}$ & 21 & 6.0 & 0.865 & $0 \%$ & $5 \%$ & $95 \%$ \\
\hline$b$ & $\begin{array}{l}\text { I encountered difficulties during the } \\
\text { creative process. }\end{array}$ & 21 & 2.2 & 1.758 & $76 \%$ & $10 \%$ & $14 \%$ \\
\hline C & $\begin{array}{l}\text { The process allowed me to express my } \\
\text { creativity. }\end{array}$ & 21 & 5.8 & 0.981 & $0 \%$ & $14 \%$ & $86 \%$ \\
\hline d & $\begin{array}{l}\text { I felt relaxed and happy during the } \\
\text { creative process. }\end{array}$ & 21 & 6.7 & 0.577 & $0 \%$ & $0 \%$ & $100 \%$ \\
\hline e & $\begin{array}{l}\text { I felt worried about how my product } \\
\text { looked. }\end{array}$ & 21 & 2.1 & 1.558 & $76 \%$ & $14 \%$ & $10 \%$ \\
\hline$f$ & $\begin{array}{l}\text { The creative process allowed me to } \\
\text { express myself. }\end{array}$ & 21 & 5.8 & 0.944 & $0 \%$ & $10 \%$ & $90 \%$ \\
\hline g & $\begin{array}{l}\text { The creative process allowed me to use } \\
\text { my fine motor skills. }\end{array}$ & 21 & 5.8 & 1.179 & $5 \%$ & $14 \%$ & $81 \%$ \\
\hline $\mathrm{h}$ & $\begin{array}{l}\text { I liked to discuss with others on how to } \\
\text { decorate the product. }\end{array}$ & 21 & 6.3 & 1.065 & $0 \%$ & $10 \%$ & $90 \%$ \\
\hline
\end{tabular}

TABLE 2: EVALUATION RESULTS OF FOOTWEAR WORKSHOPS

\begin{tabular}{|c|c|c|c|c|}
\hline \multirow{2}{*}{\multicolumn{2}{|c|}{ ITEMS }} & \multirow{2}{*}{$\mathbf{N}$} & \multicolumn{2}{|c|}{$\begin{array}{l}\text { PERCENTAGE } \\
\text { DISTRIBUTION (\%) }\end{array}$} \\
\hline & & & YES & NO \\
\hline \multirow[t]{2}{*}{ i } & $\begin{array}{l}\text { Before the workshop, did you know how to decorate } \\
\text { footwear? }\end{array}$ & 21 & $14 \%$ & $86 \%$ \\
\hline & Were you confident in making a satisfactory product? & 21 & $95 \%$ & $5 \%$ \\
\hline \multirow[t]{2}{*}{ j } & Did you enjoy the creative process? & 21 & $100 \%$ & $0 \%$ \\
\hline & Were you satisfied with the finished product? & 21 & $95 \%$ & $5 \%$ \\
\hline
\end{tabular}

\section{IMPLICATIONS OF THE STUDY}

As the population of Hong Kong ages, the health problems of the elderly are receiving much attention. Geriatric health care product producers and elderly service operators can implement the co-design process to enhance product use. This can further help improve the health of older people as well as their quality of lives.

\section{FURTHER RESEARCH}

The small sample size limits the generality of the finding. A larger scale replication study is needed. It is also worthwhile 
to compare the frequency of use of geriatric footwear for older people who participated in co-design workshop with those who did not participate in the workshop.

\section{CONCLUSION}

In this study, footwear workshops for older women are carried out to examine their personal experiences and perceptions of geriatric footwear design. The survey results indicated that the workshops have positive effects. The creative process provides personal, spiritual and social satisfaction to the older women. The process also gives the women a sense of success. These women feel very satisfied with their own creativity. In addition, they communicate well with others and have the opportunity to share their footwear decoration ideas with others. Overall, the codesign approach has positive psychological impacts on the elderly and their acceptance of the final product. This approach also better meets the aesthetic needs of the users.

\section{ACKNOWLEDGEMENT}

We would like to thank the Innovation and Technology Fund (ITF) (ITT/025/17GP) for funding this research project.

\section{References}

1. Winner S, Morgan CA, Evans JG. Perimenopausal risk of falling and incidence of distal forearm fracture. BMJ. 1989;298(6686):1486-8.

2. Arnadottir SA, Mercer VS. Effects of footwear on measurements of balance and gait in women between the ages of 65 and 93 years. Phys Ther. 2000;80(1):17-27.

3. Davis AM, Galna B, Murphy AT, Williams CM, Haines TP. Effect of footwear on minimum foot clearance, heel slippage and spatiotemporal measures of gait in older women. Gait Posture. 2016:44:43-7.

4. Ikpeze TC, Omar A, Elfar JH. Evaluating problems with footwear in the geriatric population. Geriatr Orthop Surg Rehabil. 2015;6(4):338-40.

5. Lai CS-y, Hui PC-I. Perceived values of servicelearning: a study on students engaged in a fashion- related programme. International Journal of Fashion Design, Technology and Education. 2018:1-9.

6. Au J, Lam J, Ho C. Design preferences and experience of older people's choice in fashion in Hong Kong. International Journal of Fashion Design, Technology and Education. 2016:9(3):183-91.

7. Davis A, Murphy A, Haines TP. "Good for Older Ladies, Not Me" How Elderly Women Choose Their Shoes. J Am Podiatr Med Assoc. 2013;103(6):465-70.

8. Wilkinson CR, De Angeli A. Applying user centred and participatory design approaches to commercial product development. Des Stud. 2014;35(6):614-31.

9. Sanders EB-N, Stappers PJ. Co-creation and the new landscapes of design. Co-design. 2008;4(1):5-18.

10. Steen M, Manschot M, De Koning N. Benefits of co-design in service design projects. International Journal of Design. $2011 ; 5(2)$.

11. Tzanidaki D, Reynolds F. Exploring the meanings of making traditional arts and crafts among older women in Crete, using interpretative phenomenological analysis. Br J Occup Ther. $2011 ; 74(8): 375-82$.

12. Lee YA, Sontag MS. An assessment of the proximity of clothing to self scale for older persons. Int J Consum Stud. 2010;34(4):443-8. 